\title{
THE NATURAL HISTORY OF CONGENITAL DISEASE OF THE HIP
}

\author{
J. H. WEDGE, M. J. WASYLENKO
}

From the Department of Orthopaedic Surgery, University Hospital, Saskatoon

\begin{abstract}
Fifty-four adults with eighty hips affected by congenital disease which had not been treated have been reviewed. Fifty-nine per cent of forty-two dislocated hips had fair or poor grading scores. The incidence of osteoarthritis was markedly increased in the presence of a well-developed false acetabulum. Unilateral dislocation led to valgus deformity and degenerative changes in the ipsilateral knee in seven of twenty-two patients. Dislocation did not increase the incidence of symptomatic lumbar spondylosis. The height of the dislocated head on the ilium was not found to be related to the prognosis for the hip, the knee or the lumbar spine and did not correlate with the development of the false acetabulum. Frank congenital subluxation eventually led to osteoarthritis of the hip.
\end{abstract}

Detailed descriptions of the natural history of congenital disease of the hip, particularly of complete dislocation, are not available. Most orthopaedic surgeons have impressions of how these people fare in the long term but these are usually based on comparison with the results of older methods of treatment. The increasing number of adults presenting for total hip replacement (Dunn and Hess 1976) and of older children for newer methods of reconstruction (Klisic and Jankovic 1976) makes knowledge of the natural history very pertinent. This is of particular importance because of the technical difficulties and major complications of operations (Charnley and Feagin 1973; Solomon 1977).

There are many unanswered questions concerning the natural history of congenital disease of the hip. What is the functional status of the adult with congenital dislocation? How do patients with unilateral dislocation compare to those with bilateral dislocation? How inevitable is osteoarthritis after dysplasia or subluxation? Does the degree of development of the false acetabulum correlate with the development of degenerative change? Does dislocation lead to pain in the knee? Is there a relationship between dislocation of the hip and low backache? Is there a correlation between the height of the dislocated head on the ilium and the function of the lumbar spine, the hip and the knee?

In an attempt to answer these questions we undertook a retrospective review of untreated individuals with congenital disease of the hip who were more than sixteen years of age. To avoid the bias of including only patients who presented for treatment with pain in the hip, we sought out all patients in our area who were known to have congenital disease of the hip. We did this by locating patients in whom it was an incidental finding on physical or radiological examination for other complaints, by requesting general practitioners to provide us with names of their patients known to have untreated congenital disease of the hip and by including individuals located during a previous population survey of congenital dislocation of the hip (Ives and Houston 1969).

\section{CLINICAL MATERIAL}

We located fifty-four adults with eighty hips affected by congenital dysplasia, subluxation or dislocation that had received no treatment, and personally examined forty-nine of the patients. The remaining five answered a questionnaire and had recent radiographs available. The age range was from sixteen to eighty-six years (Fig. 1). Seventeen patients had varying degrees of North American Indian ancestry.

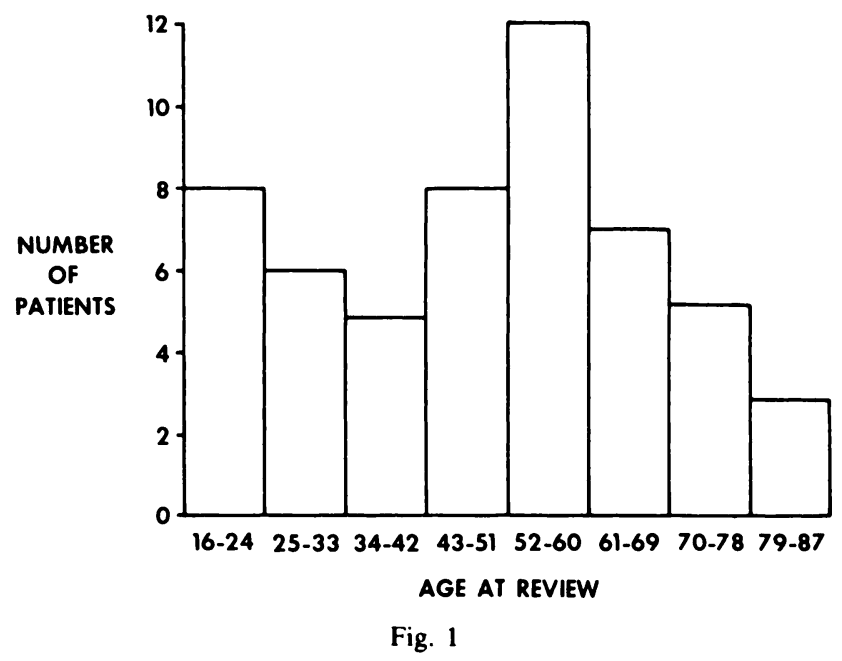

Distribution of ages of the fifty-four patients.

Nineteen patients had unilateral dislocation and ten bilateral. Three patients had dislocation on one side and dysplasia or subluxation on the other. This made a total of forty-two dislocated hips. There were nine patients with unilateral dysplasia or subluxation

J. H. Wedge, M.D., F.R.C.S.(C). \} Department of Orthopaedic Surgery, University of Saskatchewan, University Hospital, Saskatoon, M. J. Wasylenko, M.D.

Requests for reprints should be sent to Dr J. H. Wedge. 

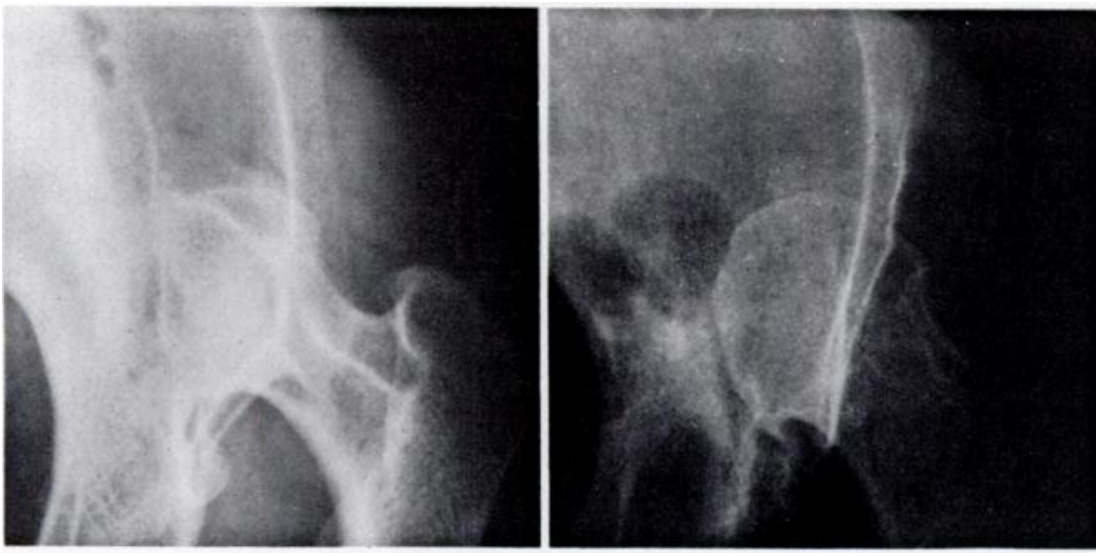

Fig. 2

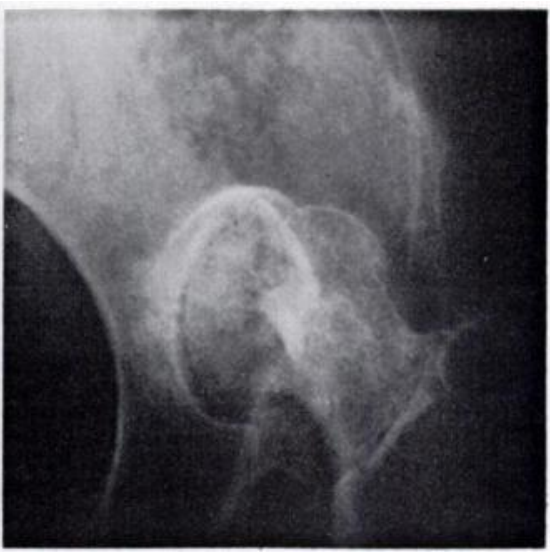

Three degrees of development of the false acetabulum.

and thirteen with bilateral disease; including the three hips with dysplasia or subluxation opposite a unilateral dislocation, this made a total of thirty-eight hips in this group.

\section{METHODS OF ASSESSMENT}

Most methods of assessing the function of the hip are designed for older patients with osteoarthritis and are heavily weighted to pain. Marked anatomical abnormality that may lead to trouble later in life can exist with an almost perfect hip score. This is one of the problems in assessing, at skeletal maturity, the results of treatment in childhood.

Table I. Derivation of the hip score*

\begin{tabular}{|l|r|}
\hline \multicolumn{1}{|c|}{ Criteria } & Points \\
\hline Absence of pain & 44 \\
Function & 47 \\
Range of movement & 5 \\
Absence of deformity & $\frac{4}{100}$ \\
\hline \multicolumn{2}{|c|}{ Score $=$ Total points $\times 0.9(+10$ if } \\
negative Trendelenberg's sign $)$
\end{tabular}

* modified from Harris (1969)

Table II. The grading of scores

\begin{tabular}{|l|c|c|}
\hline & Dislocation & $\begin{array}{c}\text { Subluxation and } \\
\text { dysplasia }\end{array}$ \\
\hline Good & $>71$ & $>79$ \\
Fair & $58-71$ & $66-79$ \\
Poor & $<58$ & $<66$ \\
\hline
\end{tabular}

We therefore selected the method of Harris (1969) and modified it by adding ten points if Trendelenberg's sign was negative (Table I). We did this so that some subluxed hips which would otherwise have received an almost perfect score should have a score reflecting the insufficiency of their abductor muscles. Dislocated hips lost points for a positive Trendelenberg's sign and the limp. Even in the absence of pain a dislocated hip could not score much higher than seventy-two. A score which reflected similar function in a subluxed hip was higher because the shortening and the limp were less. The grading of scores into good, fair and poor is shown in Table II.

The forty-two dislocated hips were graded radiologically by the degree of development of a bony socket on the ilium. Figure 2 illustrates three stages in the formation of a false acetabulum.

We developed a "dislocation index" on the anteroposterior radiograph of the pelvis (Fig. 3) so that we might correlate the height of the dislocated head with the hip score, with low backache and with the function of the knee. The normal range of this index is 36 to 42 .

\section{RESULTS}

Dislocation. Only seventeen of the forty-two dislocated hips (41 per cent) were rated good (Table III). The score

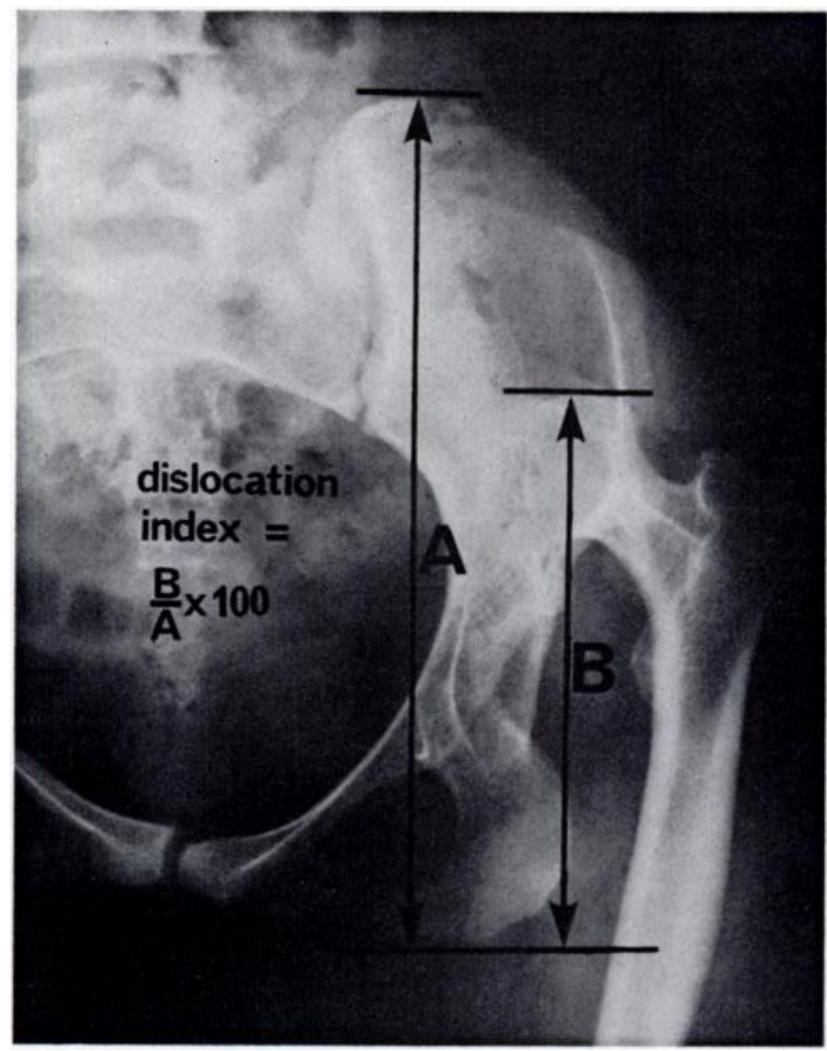

Fig. 3

Method of measuring the dislocation index. 
Table III. The results of grading for eighty hips

\begin{tabular}{|l|c|c|}
\hline \multicolumn{1}{|c|}{ Score } & Dislocation & $\begin{array}{c}\text { Subluxation and } \\
\text { dysplasia }\end{array}$ \\
\hline Good & 17 & 16 \\
Fair & 6 & 4 \\
Poor & 19 & 18 \\
\hline Total numbers of hips & 42 & 38 \\
\hline
\end{tabular}

Table IV. Comparison of grading in unilateral and bilateral dislocations

\begin{tabular}{|l|c|c|}
\hline \multicolumn{1}{|c|}{ Score } & Unilateral & Bilateral \\
\hline Good & 10 & 7 \\
Fair & 4 & 2 \\
Poor & 8 & 11 \\
\hline Total number of hips & 22 & 20 \\
\hline
\end{tabular}

did not seem to correlate with age but rather with the development of the false acetabulum and the presence of degenerative changes. The unilateral dislocations fared slightly better than the bilateral, with 45 per cent and 35 per cent good respectively (Table IV).

Subluxation and dysplasia. Forty-two per cent of the hips in this group had a good score (Table III). In contrast to dislocated hips, the patients tended to be younger and once pain started it often quickly became more severe. Whereas dislocation resulted in degenerative changes in one quarter of cases, nearly always in a large false acetabulum, dysplasia and subluxation led much more frequently to frank osteoarthritis. The hip scores remained good until these degenerative changes developed.

Figure 4 illustrates this point in a woman who began having occasional mild aching pain in her subluxed hip at twenty-six years of age. The pain remained much the same over the next eighteen years until at forty-four years it increased in severity. By forty-six years she was considerably disabled. Over the next two years the changes progressed to the point where she required a resurfacing arthroplasty to relieve her symptoms.

False acetabulum and osteoarthritis. Twelve dislocated hips had no demonstrable false acetabulum, thirteen had moderate development and in seventeen it was well developed. When there was either moderate development or none, 48 per cent of the hips were graded fair or poor, but when the false acetabulum was well developed 76 per cent were thus rated.
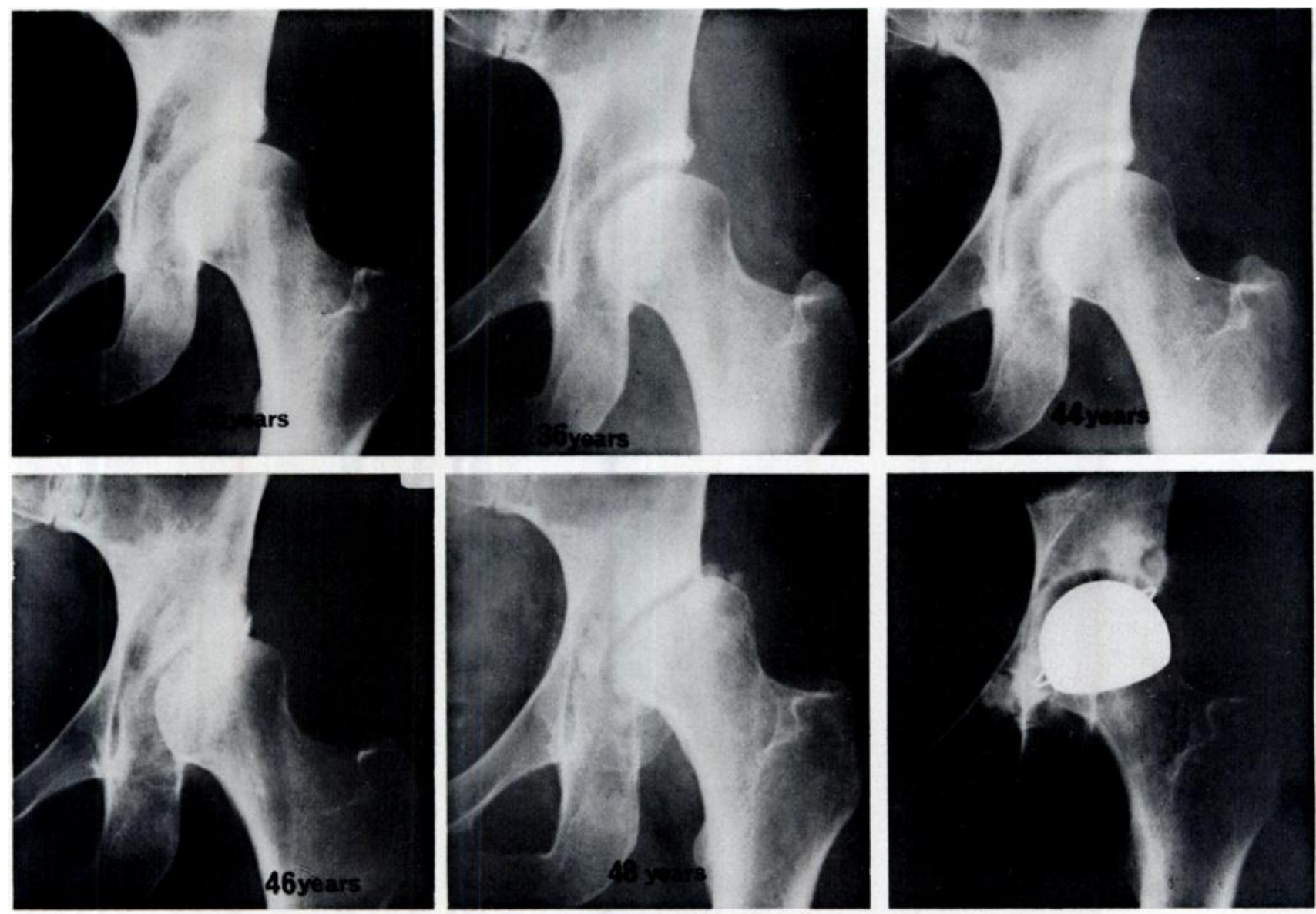

Fig. 4

Sequential radiographs in a woman with mild subluxation (see text). 


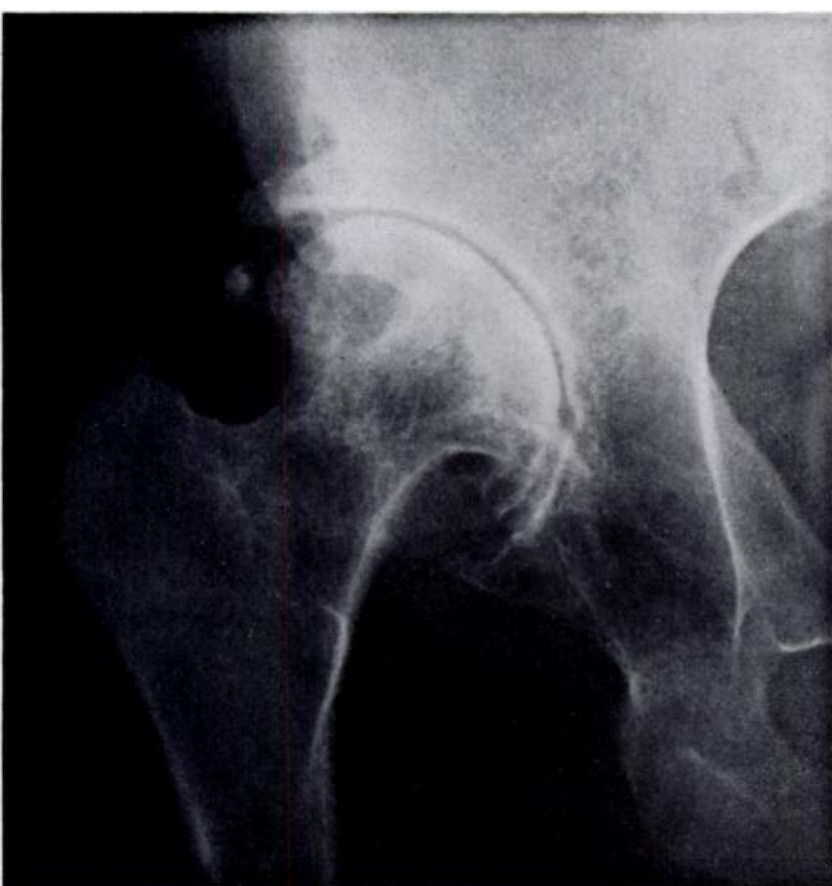

Fig. 5

Osteoarthritis in the false acetabulum in a fifty-year-old woman

Osteoarthritis developed in thirteen of the fortytwo dislocated hips (Fig. 5). Like arthritis occurring in the true acetabulum, radiographic features included cysts, sclerosis, flattening of the head, formation of osteophytes and loss of joint space. Ten of the thirteen hips with degenerative changes were rated poor. Those hips with a well-developed false acetabulum were much more likely to develop osteoarthritis and have a poor score.

Pain and deformity in the knee. Eight patients had significant dysfunction of the knee unrelated to any previous injury. All eight had complete dislocation of the hip and seven had valgus malalignment of the knee on the same side as the unilateral dislocation. It would appear that dropping the pelvis to the side of the dislocation during walking results in repeated excessive valgus stress to the knee. An unexplained finding in several patients was degenerative change in the medial rather than the lateral compartment of the valgus knee (Fig. 6).

Backache and spondylosis. We found no more backache than one would expect to find in a population of similar age. Only three of the fifty-four patients had backache, and this was associated with increased lumbar lordosis or functional scoliosis due to unequal leg lengths.

Height of the dislocated head. The "dislocation index" (Fig. 3) averaged 69 in the dislocated hips (normal range, 36 to 42 ). In this series there was no correlation between the height of the dislocated head and the hip score, backache, dysfunction of the knee or development of the false acetabulum.

\section{DISCUSSION}

The assessment of impaired function in complete dislocation is very subjective. However, 60 per cent of hips seem to present significant problems. The remaining 40 per cent give no pain but produce an abnormal gait with decreased agility, an important consideration in modern society. In some of our older patients dislocation, whether unilateral or bilateral, was compatible with acceptable function and little discomfort. Unilateral dislocation has been thought in the past to lead to more difficulty than bilateral dislocation. Although in unilateral dislocation there is a tendency for more problems affecting the knee there does not seem to be much difference overall between unilateral and bilateral dislocation.

It is not known what factors are responsible for the degree of development of a false acetabulum. Perhaps more active individuals put more stress on the ilium, resulting in greater development of the false joint.
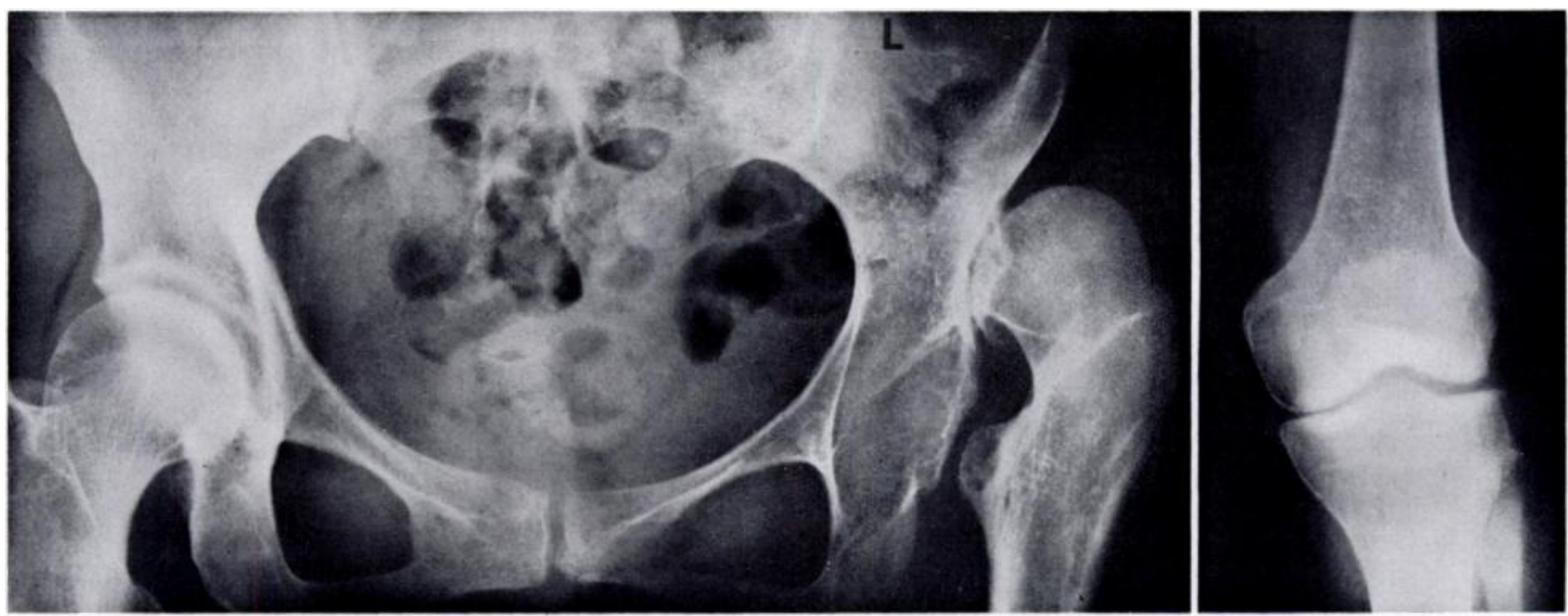

Fig. 6

Unilateral dislocation in a fifty-eight-year-old woman with degenerative changes in the ipsilateral knee. 
Well-developed false acetabula are more prone to degenerative changes and poor function. It is our impression that the development of the false joint occurs by early adolescence and changes little with age.

Subluxation inevitably leads to difficulty which is proportional to the degree of displacement and the age of the patient (Wiberg 1939). The altered mechanics due to the concentration of forces through the reduced weight-bearing area presumably results in early osteoarthritis.

We would like to acknowledge the valuable assistance of Dr C. S. Houston.

\section{REFERENCES}

Charnley, J., and Feagin, J. A. (1973) Low-friction arthroplasty in congenital subluxation of the hip. Clinical Orthopaedics and Related Research, 91, 98-113.

Dunn, H. K., and Hess, W. E. (1976) Total hip reconstruction in chronically dislocated hips. Journal of Bone and Joint Surgery, 58-A, 838-845.

Harris, W. H. (1969) Traumatic arthritis of the hip after dislocation and acetabular fractures: treatment by mold arthroplasty. Journal of Bone and Joint Surgery, 51-A, 737-755.

Ives, E. J., and Houston, C. S. (1969) Congenital dislocation of the hip in northern Saskatchewan Indians. International Congress Series No. 191, p. 69. Amsterdam: Excerpta Medica.

Klisic, P., and Jankovic, L. (1976) Combined procedure of open reduction and shortening of the femur in treatment of congenital dislocation of the hips in older children. Clinical Orthopaedics and Related Research, 119, 60-69.

Solomon, L. (1977) Total joint replacement for late congenital dislocation of the hip. Journal of Bone and Joint Surgery, 59-B, 254.

Wiberg, B. (1939) Studies on dysplastic acetabula and congenital subluxation of the hip joint, with special reference to the complication of osteo-arthritis. Acta Chirurgica Scandinavica, 83, Supplement 58. 